\title{
Intravesical foreign bodies: a case report and a review of the literature
}

This article was published in the following Dove Press journal:

International Medical Case Reports Journal

2 May 2011

Number of times this article has been viewed

\author{
Eshiobo Irekpita' \\ Peter Imomoh ${ }^{2}$ \\ Emeka Kesieme ${ }^{3}$ \\ Vincent Onuora ${ }^{4}$ \\ 'Department of Surgery, Ambrose \\ Alli University, Ekpoma, Nigeria; \\ ${ }^{2}$ Department of Family Medicine, Irrua \\ Specialist Teaching Hospital, Irrua, \\ Nigeria; ${ }^{3}$ Department of Surgery, Irrua \\ Specialist Teaching Hospital, Irrua, \\ Nigeria; ${ }^{4}$ Department of Surgery, \\ Igbenedion University, Okada, Nigeria
}

Aim: We report a case of intravesical polyvinyl-coated electric wire in the urinary bladder. Case report: A 34-year-old man presented in our clinic with irritative lower urinary tract symptoms. Three weeks earlier he had seen and felt a wire in his urethra of which he was unaware of the origin. Radiologic evaluation revealed an electric wire completely coiled up in the urinary bladder. It was removed through a suprapubic cystotomy.

Discussion: Patients are usually too ashamed to admit the cause of an intravesical foreign body, which is often sexual or erotic in origin. Radiologic evaluation usually reveals the nature and size of the foreign body in the bladder of patients evaluated for recurrent urinary tract infection. Open surgery or an endoscopic approach may be used for their extraction.

Keywords: intravesical, electric wire, complications, treatment

\section{Introduction}

Most organs of the genitourinary system, except for the male external genitalia, are well protected by the surrounding structures. ${ }^{1}$ For instance, the bladder lies directly behind the pelvic bone and anterior to the rectum, which makes it relatively inaccessible. The bladder functions in the storage and intermittent evacuation of urine with a capacity of about $450-750 \mathrm{~mL}$. The urethra, through which the contents are evacuated, measures about $16-20 \mathrm{~cm}$ in males, which makes the presence of a foreign body in the male urinary bladder an enigma. ${ }^{2}$

Foreign bodies in the urinary bladder may occur by self-insertion or migration from the neighboring organs. ${ }^{3}$ They vary from tissue originating from adjacent organs ${ }^{4}$ to metallic objects such as electric wires. ${ }^{5}$ The reasons for their presence in the urinary bladder also vary from sexual and erotic manipulations ${ }^{6}$ to iatrogeny ${ }^{7}$ and complimentary and alternative medicine practice. ${ }^{8}$

A foreign body in the urinary bladder, according to Jung et $\mathrm{al}^{4}$ is a rare occurrence. Martinez-Valls et $\mathrm{al}^{9}$ describe the condition as being exceptional and not a common emergency. From a MedLine search, most cases of foreign bodies in the urinary bladder in Nigeria have been due to migration of intrauterine contraceptive devices and have been presented as case reports. We report the case of a 34-year-old man with polyvinyl chloride (PVC)-coated electric wire in the lumen of the urinary bladder, followed by a review of the literature.

\section{Case report}

A 34-year-old man presented in our clinic with a 2-week history of frequency, urgency, and dysuria. The diagnosis of urinary tract infection was made, and he was requested 
to do a urine microscopy culture and sensitivity and then placed on empirical antimicrobial therapy. He subsequently presented with the same symptoms in addition to severe suprapubic tenderness and fever. This time, he felt and saw the tip of a wire in his urethra. All attempts at self-removal had failed.

Ultrasonography was carried out, which suggested an intravesical foreign body without a urethral extension. The bladder wall was shown to be thickened. There was no evidence of intravesical calculus. The radiologist suggested that a plain pelvic X-ray be obtained to establish the nature of the intravesical foreign body. The X-ray showed a radiopaque intravesical substance fully coiled in the bladder without a urethral extension. This suggested an electric wire and helped in estimating the size and length of the foreign body (Figure 1).

A suprapubic cystotomy was performed using a Pfannenstiel incision. Finger inspection confirmed that the foreign body was intravesical without a urethral extension. With minimal effort, the wire, which was coated with PVC, measured about $46 \mathrm{~cm}$, and was knotted close to one end (Figure 2), was extracted. There was no phosphatic encrustation or deposit of blood on it. Bladder inspection did not reveal a vesical calculus.

\section{Discussion and review of the literature}

Foreign bodies localized to the urogenital tract represent a relatively rare pathology and, according to Mischianu et $\mathrm{al}^{10}$ in many cases, have legal implications. This is particularly so for the urinary bladder, as the urethra and ureters may be catheterized for a reasonable period because they are only conduit pipes. Their presence in the urinary tract predisposes to infection, calculus formation, and bladder outlet obstruction, all of which may lead to renal impairment.

Foreign bodies in the urinary bladder may occur by selfinsertion or migration from the neighboring organs. ${ }^{11}$ This patient did not volunteer a reasonable history to enable a fair assertion of the method of insertion. That is not unusual, as, according to Aliabadi et $\mathrm{al}^{12}$ most patients are usually too ashamed to admit they had inserted an object for autoerotic, psychiatric, therapeutic, or any other reasons. Patients present when symptoms develop or there are complications. The length of the male urethra makes it impossible to assume that a foreign body found its way into the bladder unknown to the patient, unlike in females in a primitive agricultural setting. According to van Ophoven and deKernion ${ }^{13}$ the most common motive associated with the insertion of foreign bodies into the genitourinary tract is sexual or erotic in nature. In adults, they opine that it is commonly caused by insertion of objects used for masturbation, which is frequently associated with a mental health disorder. ${ }^{14}$ Such patients are also known to be prone to genital self-emasculation injuries, ${ }^{15}$ so they need to be identified and have psychiatric assessment. Our patient refused this.

The variety of foreign bodies inserted into, or attached externally to, the genitourinary tract defies imagination and includes all types of objects. ${ }^{6}$ They vary with societies, levels of development, the aim of insertion, and cause. Osca et $\mathrm{al}^{16}$ reported eight cases of self-inserted foreign bodies in the lower urinary tract treated from 1976 to 1990, of which five were intravesical. Objects found include electric cable, tweezers, a hair pin, a drawing pin, pebbles, and a paper clip. Kochakarn and Pummanagura ${ }^{17}$ studied 78 patients, and objects inserted included cotton swabs, tampons, paper clips, and pen casing. According to Kochakarn and Pummanagura, as most of Thailand is an agricultural environment, some small living organisms, such as leeches, could be found as intravesical foreign bodies in females. Rafique ${ }^{7}$ has identified the intravesical foreign bodies as copper wire, a carrot, a lead pencil, an intrauterine device, surgical gauze, pieces of Foley catheter, and a Teflon beak of resectoscope sheath. There is clearly a remarkable variation in objects in relation to intravesical foreign bodies and their causes in different societies.

The presentation of intravesical foreign bodies from iatrogenic causes requires a high index of suspicion for diagnosis, as the foreign body may remain in the body for a long period before symptoms develop. This duration is the period of migration from the primary site of introduction to the bladder lumen. For instance, Izumi et $\mathrm{al}^{8}$ reported a case of an acupuncture patient with a bladder stone of $2 \mathrm{~cm}$ with a needle core who had symptoms of benign prostatic hyperplasia for 10 years. Another example is the case report by Irisawa et $\mathrm{al}^{18}$ of a 66 -year-old male who underwent a rectal operation 6 years earlier and subsequently presented with a surgical needle in the bladder. It is supposed that it took the needle about 6 years to migrate from the perirectal tissue to the bladder. Far more common are case reports of the migration of intrauterine contraceptive devices. ${ }^{19,20}$ The need for a high index of suspicion is reinforced by the rarity of this condition.

The symptoms of intravesical foreign body are remarkably constant and are usually as a result of bladder irritation and, when the foreign body is large, reduced bladder capacity. Hematuria may occur from trauma due to self-manipulation 


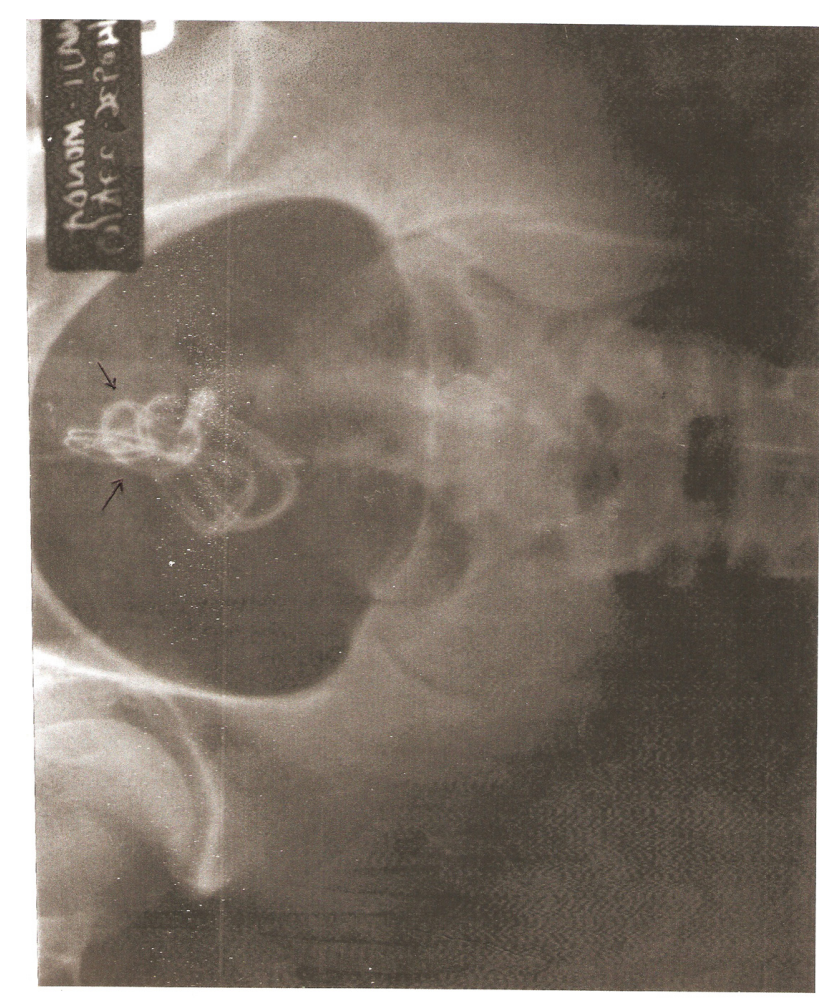

Figure I X-ray of intravesical foreign body.

or rough objects that injure the bladder wall. These symptoms are most commonly irritative ${ }^{17}$ but may also be obstructive if there is an extension of the foreign body into the urethra ${ }^{21}$ and this is usually accompanied by copious bloody discharge. Suprapubic pain, waste pain, and fever may occur in longstanding cases.

A wide variety of complications may follow the presence of foreign bodies in the urinary bladder. Foreign bodies in the urinary tract increase the risk of urinary tract infection. ${ }^{22}$ Such infections are often recurrent as a result of bacteria persistence within or on the foreign body and sometimes as a result of poor drainage. The risk of endotoxemia should always be borne in mind in the process of extraction of the foreign body. Complications such as calculus formation have been widely reported in association with migrated intrauterine contraceptive devices and surgical needles. ${ }^{23-25}$

Life-threatening complications of intravesical foreign bodies are rare but do occur. Ito et $\mathrm{al}^{26}$ reported in 2009 a case of intravesical foreign body with a vesical rupture and peritoneal invasion. To the authors' knowledge, there had been only 10 similar cases in Japan at the time of their report. Severe infection and obstruction may lead to renal insufficiency, ${ }^{27}$ whereas urethral injury during insertion or self-extraction may predispose to urethral stricture formation.
Radiologic images are next only to a high index of suspicion in the evaluation of patients with intravesical foreign bodies. The extent and modality required depends on the type of foreign body and the presence or otherwise of complications. Radiologic evaluation is necessary to determine the exact size, number, and nature of the foreign body. Ultrasonography is usually able to localize the foreign body to the bladder and determine the exact size and number but is unable to evaluate the exact nature (Figure 1). Plain abdominal X-ray is, however, able to classify the objects into radiopaque and radiolucent, and therefore to a large extent determine their nature, eg, radiopaque metals (Figure 2). In the presence of bladder perforation, computed tomographic cystography is a reliable diagnostic tool where enhancement of the bladder contents is necessary. ${ }^{28}$ Cystoscopy confirms the diagnosis, and some foreign bodies are successfully removed during the process. ${ }^{29}$

Foreign bodies in the urinary bladder represent a urologic challenge that requires prompt management ${ }^{7}$ and should be treated as emergencies. The wide variety of techniques for

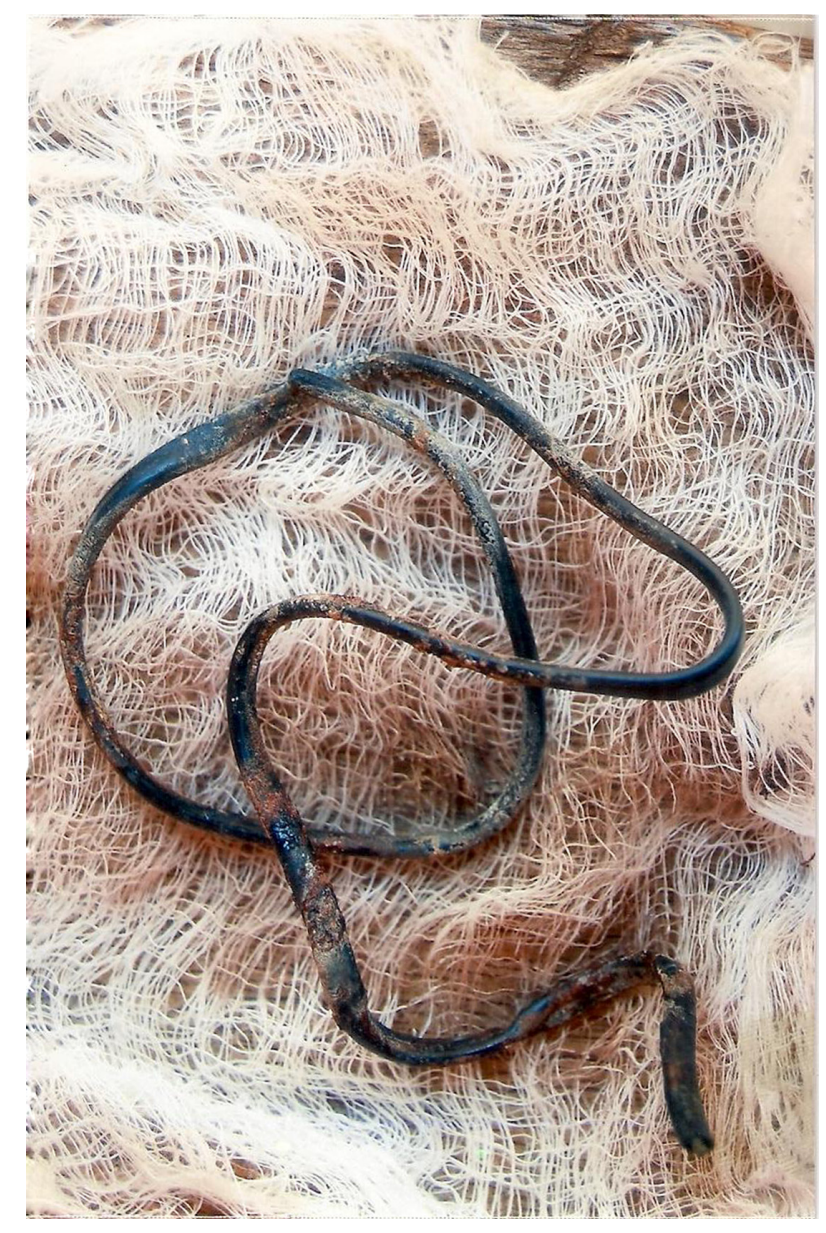

Figure 2 Intravesical foreign body. 
removal of intravesical foreign bodies indicates the ingenuity with which urologists have approached the subject. Broadly, these are classified into endoscopic and open surgical approaches, the method used usually depending on the nature and size of the object and the available expertise and equipment. ${ }^{7}$ Endoscopic and minimally invasive techniques should be encouraged. However, in many cases, management cannot be endoscopic and it is necessary to use the classical method.

The simplest endoscopic approach to extraction of an intravesical foreign body is cystoscopy and retrieval with biopsy forceps. This is suitable for small objects such as intrauterine contraceptive devices, as reported by Olaore et $\mathrm{al}^{19}$ Sharma et $\mathrm{al}^{11}$ and Forde et $\mathrm{al}^{30}$ in their different works. A more complex cystoscopic approach has been described by Reddy and Daniel. ${ }^{31}$ The cystoscope acts as the optical device and a laparoscope port is introduced suprapubically under vision for extraction of complex foreign bodies while the bladder is insufflated with carbon dioxide. Laparoscopic approach to removal has also been described. ${ }^{4}$ When there is encrustation or stone formation on the foreign body, internal lithotripsy or stone forceps may be used to crush the stone in order to facilitate extraction of the foreign body. Sometimes, open surgery is required because the foreign body is too large or its nature makes this imperative, as in the case of our patient. This may also be done when the manpower or equipment is not available.

\section{Conclusion}

The presence of a foreign body in the urinary bladder is rare and exceptional and therefore requires a high index of suspicion for diagnosis. Presentation is sometimes delayed with complications that may be life-threatening. It should be considered in young patients with recurrent urinary tract infection and poor response to antibiotic therapy. Such patients should have radiologic evaluation in order to facilitate diagnosis and treatment. Where an underlying psychological abnormality is suspected, psychiatric assessment should be carried out.

\section{Disclosure}

The authors report no conflicts of interest and did not request or receive any form of financial support for this project.

\section{References}

1. Irekpita E, Omokhan S, Dongo AE, Onuora VC. Genito-urinary injury in Irrua, Nigeria. ACR. 2008;2:50-56.

2. Eke N, Okpani AO. Extra uterine traslocated contraceptive device: a presentation of five cases and revisit enigmatic issues of iatrogenic perforation and migration. Afr J Reprod Health. 2003;7(3):117-1123.
3. Sharma UK, Rauniyar D, Shar WE. Intra vesical foreign body: case report. KathMandu Univ Med J. 2006;4(3):342-344.

4. Jung US, Lee JH, Kyung MS, et al.Laparoscopic removal of an intravesical foreign body after laparascopically assisted vaginal hysterectomy, a case report and review of the literature. Surg Laparosc Endosc Percutan Tech. 2008;18(4):420-427.

5. Osca JM, Broseta E, Server G, et al. Unusual foreign bodies in the urethra and bladder. Br J Urol. 1991;68(5):510-512.

6. Trehan RK, Haroon A, Memon S, Turna D. Successful removal of a telephone cable, a foreign body through the urethra into the bladder: a case report. J Med case Reports. 2007;1:153.

7. Rafique M. Intravesical foreign bodies: review and current management strategies. Urol J. 2008;5(4):223-231.

8. Izumi K, Takizawa A, Udagawa K, et al. Bladder stone secondary to migration of an acupuncture needle. Hinyokika Kiyo. 2008;54(5): 365-367.

9. Martinez-Valls PL, Honrubia VB, Rodriguez TA, et al. Voiding symptoms as presentation of an intravesical foreign body. Arch Esp Urol. 2008,61(7):781-785.

10. Mischianu D, Ilie CP, Madan V, et al. Foreign bodies in the urogenital tract-between iatrogeny and autoerotism. Chirurgia (Bucur). 2007;102(6):699-707.

11. Sharma UK, Rauniyar D, Shar WF. Intravesical foreign body: case report. Kathmandu Univ Med J. 2006;4(3):342-344.

12. Aliabadi H, Cass AS, Gleich P, Johnson CF. Self-inflicted foreign bodies involving lower urinary tract and male genitals. Urology. 1985;26(1):12-16.

13. Van Ophoven A, deKernion JB. Clinical management of foreign bodies of the genito-urinary tract. Urology. 2000;164(2):274-287.

14. Garcia RV, Vareal SM, Fernandez GL. Urethra foreign bodies: apropos 2 cases. Arch Esp Urol. 1999,52(1):74-76.

15. Patel SR, Tharasechan S, Handel LN, et al. Bilateral manual externalization of testis with self castration in patient with prion disease. Urology. 2007;70(3):590.e15-e16.

16. Osca JM, Broseta E, Server G, et al. Unsual foreign bodies in the urethra and bladder. Br J Urol. 1991;68(5):510-512.

17. Kochakarn W, Pummanagura W. Foreign bodies in the female bladder: 20 year experience in Ramathibodi Hospital. Asian J Surg. 2008; 31(3):130-133.

18. Irisawa C, Yamaguichi O, Shiraiwa $\mathrm{Y}$, et al. A case of a foreign body in the urinary bladder-surgical suture needle was found in the urinary bladder. Hinyokika Kiyo. 1991;37(11):154-159.

19. Olaore JA, Shittu OB, Adewole IF. Intravesical lippes loop following insertion for the treatment of Ashermans syndrome: a case report. Afr J Med Sci. 1999;28(3-4):2007-2008.

20. Mustafa M. Erosion of an intra-uterine contraceptive device through the bladder wall causing calculus. Management and review of the literature. Urol Int. 2009;82(3):370-371.

21. Stravodimos KG, Koritsiadis G, Koutalellis G. Electric wire as foreign body in a male urethra: a case report. J Med Case Report. 2009;3(3):49.

22. Jensen CS, Walter S. Urinary tract infections: occurrence, causes and prevention. Ugeskr Laeger. 2007;169(49):4265-4268.

23. Ituraide CA, Goza LF, Beyries TW, et al. Double bladder lithiasis from an intrauterine device: report one case. Arch ESP Urol. 2004;57:160-162.

24. Guvel S, Tekin MI, Kiliac F, et al. Bladder stones around a migrated and missed intrauterine contraceptive device. Int J Urol. 2001;8(2): 78-79.

25. Dermici D, Ekmekcioglu O, Demitras A, Gulmez I. Big bladder stones around an intravesical migrated intrauterine contraceptive device. Int Urol Nephrol. 2003;35(4):495-496.

26. Ito $\mathrm{H}$, Ninomiya A, Furuuchi J, et al. A case of intravesical foreign body with a vesical rupture invading the peritoneal cavity: a case report. Hinyokika Kiyo. 2009;55(5):425-427. 
27. Jacobs BL, Matoka DJ, Maranchie JK. Renal insufficiency secondary to delayed presentation of a retained foreign body. Can J Urol. 2009;16(3):4697-4700.

28. Shoab RF, Anwar F, Barron D. Foreign body in the urinary bladder: early CT cystogram is investigation of choice. Pak Med Assoc. 2008;58(5):277-278.

29. Kim ED, Moty A, Wilson DD, Zeagler D. Treatment of lower urinary tract obstruction secondary to an expandable foam sealant. Urology. 2002;60(1):164.
30. Forde JC, Casey RG, Grainger R. An unusual penpal: case report and literature review of posterior urethral injuries secondary to foreign body insertion. Can J Urol. 2009;16(4):4757-4759.

31. Reddy BS, Daniel RD. A novel laparoscopic technique for removal of foreign bodies from urinary bladder using carbondioxide insufflation. Surg laparosc Endosc Percutan Tech. 2004;14(4):238-239.

International Medical Case Reports Journal

\section{Publish your work in this journal}

The International Medical Case Reports Journal is an international, peer-reviewed open-access journal publishing original case reports from all medical specialties. Previously unpublished medical posters are also accepted relating to any area of clinical or preclinical science. Submissions should not normally exceed 2,000 words or
4 published pages including figures, diagrams and references. The manuscript management system is completely online and includes a very quick and fair peer-review system, which is all easy to use. Visit http://www.dovepress.com/testimonials.php to read real quotes from published authors.

Submit your manuscript here: http://www.dovepress.com/international-medical-case-reports-journal-journal 